\title{
Integration of QFD, AHP, and LPP methods in supplier development problems under uncertainty
}

\author{
Zahra Shad ${ }^{1}$, Emad Roghanian ${ }^{1}$ and Fatemeh Mojibian ${ }^{2 *}$
}

\begin{abstract}
Quality function deployment (QFD) is a customer-driven approach, widely used to develop or process new product in order to maximize customer satisfaction. Last researches used linear physical programming (LPP) procedure to optimize QFD; however, QFD issue involved uncertainties, or fuzziness, which requires taking them into account for more realistic study. In this paper a set of fuzzy data is used to address linguistic values parameterized by triangular fuzzy numbers. The proposed integrated approach includes analytic hierarchy process (AHP), QFD, and LPP to maximize overall customer satisfaction under uncertain conditions and apply them in the supplier development problem. The fuzzy AHP (FAHP) approach is adopted as a powerful method to obtain the relationship between the customer requirements (CRs) and engineering characteristics (ECS) to construct the house of quality (HOQ) in QFD method. LPP is used to obtain the optimal achievement level of the ECs and subsequently the customer satisfaction level under different degrees of uncertainty. The effectiveness of proposed method will be illustrated by an example.
\end{abstract}

Keywords: Quality function deployment; Fuzzy; Analytic hierarchy process; Linear physical programming; Supplier development

\section{Introduction}

The increasing global competition and cooperation and the vertical disintegration of production activities have created the logistical challenge of coordinating the entire supply chain (SC) effectively, in upstream to downstream activities (Gebennini et al. 2009). Supply chain management (SCM) integrates suppliers, manufacturers, distributors, and customers to meet final consumer needs and expectations efficiently and effectively (Cox 1999).

Quality function deployment (QFD) was developed by Yoji Akao in the 1960s. The basis of QFD is to obtain and translate customer requirements into engineering characteristics and subsequently, into part characteristics, process plans, and production requirements. This paper concentrated on the house of quality (HOQ) which translates customer requirements into the engineering characteristics. By better managing the SC, companies can increase their customers' satisfaction and

\footnotetext{
* Correspondence: F.mojibian@modares.ac.ir

${ }^{2}$ Department of Management and Economics, Tarbiat Modares University, Jalal Ale Ahmad Highway, P.O.BOX: 14115-111, Tehran, Iran

Full list of author information is available at the end of the article
}

achieve sustainable business success. SC has different levels and each level can be considered as a customer of the previous level in which customer satisfaction should be maximized. QFD can be used as a useful method to translate the requirements of each level to the engineering characteristics (ECs) of the previous level. The analytic hierarchy process (AHP) method can be used as a powerful multi-criteria tool to extract the relationships between the requirements of each level and ECs of the previous level. Humans are often uncertain in assigning the evaluation scores in crisp AHP, so fuzzy analytic hierarchy process (FAHP) can capture this difficulty. Although QFD implementation has extended recently, a few researchers focused in the supply chain (e.g., Zarei et al. 2011, Hassanzadeh Amin and Razmi 2009).

Satisfying customer requirement is a multi-objective optimization problem. Different optimization methods have been applied in the field of QFD to maximize customer satisfaction. Mathematical programming is one of these optimization methods. The linear programming model is used to maximize the overall customer satisfaction (e.g., Chen and Ko 2009; Lai et al. 2007). Park 
and Kim (1998) used integer programming to optimize product design in the QFD. Chen and Weng (2006) used goal programming to determine the fulfillment levels of the design requirements in the QFD. Delice and Güngör (2009) applied mixed integer linear programming (MILP) to acquire the optimized solution of alternative customer requirements (CRs). Chen and Ko (2010) consider the close link between the four phases using the means-end chain (MEC) concept to build up a set of fuzzy linear programming models to determine the contribution levels of each 'how' for customer satisfaction.

Bhattacharya et al. (2010) present a concurrent engineering approach integrating AHP with QFD in combination with cost factor measure (CFM) which has been delineated to rank and subsequently selects candidatesuppliers under multiple conflicting-in-nature criteria environment within a value-chain framework. Raissi et al. (2012) prioritize engineering characteristic in QFD using fuzzy common set of weight. Lai et al. (2006) used linear physical programming (LPP) as an effective multiobjective optimization method to optimize QFD. In this paper we extended Lai et al.'s (2006) approach by using fuzzy numbers instead of the crisp numbers to build HOQ. We used HOQ with triangular fuzzy numbers to extract mathematical model to deal with the fuzziness of the problem to achieve the optimal values of the ECs under different degrees of uncertainty.

Due to the high importance of the SCM, the aim of this paper is to develop a useful approach by integrating fuzzy AHP, fuzzy QFD (FQFD), and LPP to obtain the optimal values of the ECs of the suppliers. Supplier development is an important issue in the context of the SCM. Also, supplier development is a multi-criterion decision making (MCDM) problem which includes both qualitative and quantitative factors (e.g., Xia and $\mathrm{Wu}$ 2007; Chan and Kumar 2007).

In this section literature review of QFD, fuzzy AHP, and LPP methods, and applying LPP with QFD and fuzzy linear programming are presented. In Section 'Proposed methodology,' we present the proposed methodology and illustrated it in solving a numerical example in Section 'Numerical example'. In Section 'Discussion of results', the obtained results are discussed and finally in the last section (Section 'Conclusion'), the conclusion is presented.

\section{Quality function deployment}

QFD aims at identifying the customers together with their demands for the product, which are translated into product characteristics. QFD methodology has introduced twofold principles in product development. First, the needs of the customer should be carefully considered during the development process, Secondly, the importance of the different product characteristics should be analyzed and ranked (Bevilacqua et al. 2006).

Many researchers applied QFD to present new product or to improve product design as follows: Fung et al. (2005) applied an asymmetric fuzzy linear regression approach to estimate the functional relationships for product planning based on QFD. Kahraman et al. (2006) proposed a fuzzy optimization model based on FQFD to determine the product engineering requirements in designing a product. Soota et al. (2011) propose a method to foster product development using combination of QFD and analytic network process (ANP). Sener and Karsak (2011) combined fuzzy linear regression and fuzzy multiple objective programming for setting target levels in the QFD. Based on the Kano's category of design requirements, Chen and Ko (2008) presented a fuzzy nonlinear model to determine the performance level of each design requirements to maximize customer satisfaction. Raharjo et al. (2008) applied AHP to overcome the priorities change over time in the QFD. Sharma and Rawani (2008) develop a post-HoQ model through a well-defined and structured approach to comprehensive matrix and SWOT analysis. Raissi et al. (2011) proposed a novel methodology using common set of weight (CSW) method as a well-known technique in DEA to aggregate each of the requirements expressed by customers and comparisons among the product produced by own company with competitive products.

In the supply chain field, researchers used QFD as an effective decision making tool as follows: Bottani and Rizzi (2006) proposed a FQFD approach to deploy HOQ to efficiently and effectively improve the logistic process. Bottani (2009) presented an original approach to show the applicability of the QFD methodology to enhance the agility of enterprises. Zarei et al. (2011) studied QFD application to identify viable lean enabler for increasing the leanness of food chain. Yousefi et al. (2011) propose an original approach for the management tools selection based on the quality function deployment approach, a methodology which has been successfully adopted in development of new products.

\section{Fuzzy analytic hierarchy process}

AHP is a decision support tool that can adequately represent qualitative and subjective assessments under the multiple criteria decision making environment. AHP is strongly connected to human judgment, and pair-wise comparisons in AHP may cause an assessment bias of the evaluator, which makes the comparison judgment matrix inconsistent (Aydogan 2011). Because of this problem, using the fuzzy set theory can solve evaluation bias problem in AHP. Various applications of the FAHP can be found to solve MCDM problems. Kahraman et al. (2004) used FAHP to compare catering firms. Chan 
and Kumar (2007) applied FAHP for solving the global supplier selection problem. Haghighi et al. (2010) applied FAHP to prioritize factors that impact electronic banking development in Iran. Rung Yu and Shing (2013) propose a two-stage fuzzy logarithmic preference programming with multi-criteria decision making in order to derive the priorities of comparison matrices in the AHP and the ANP.

Different methods of FAHP were employed to extract the weight of criteria based on pair-wise comparison matrices. Extent analysis method proposed by Chang $(1992,1996)$ is a popular approach to determine the weight of criteria (e.g., Kahraman et al. 2004; Haghighi et al. 2010).

Geometric mean technique proposed by Buckley (1985) also was used to define the fuzzy geometric mean and fuzzy weights of each criterion (e.g., Chen et al. 2008; Güngör et al. 2009). After constructing pair-wise comparison matrices, $(\tilde{\mathbf{D}})$ according to geometric mean technique by using Equations 5 and 6, we can define the fuzzy weights of each criterion as following:

$$
\tilde{\mathbf{D}}=\left[\begin{array}{ccc}
1 & \tilde{d}_{12} \cdots & \tilde{d}_{1 n} \\
\vdots & \ddots & \vdots \\
\tilde{d}_{n 1} & \tilde{d}_{n 2} \cdots & 1
\end{array}\right]=\left[\begin{array}{ccc}
1 & \tilde{d}_{12} \cdots & \tilde{d}_{1 n} \\
\vdots & \ddots & \vdots \\
1 / \tilde{d}_{1 n} & 1 / \tilde{d}_{2 n} \cdots & 1
\end{array}\right]
$$

where $\tilde{d}_{i j}=\left\{\begin{array}{lr}\text { triangular fuzzy number }, & i \neq j \\ 1 & i=j\end{array}\right.$.

A fuzzy number $\tilde{d}$ on $\mathbb{R}$ to be a triangular fuzzy number if its membership function $\mu_{\tilde{d}}(x): \mathbb{R} \rightarrow[0,1]$ can be defined by the following equation:

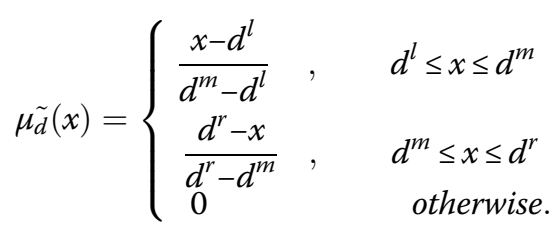

Let $\tilde{a}$ and $\tilde{b}$ be two triangular fuzzy numbers parameterized by the triplet $\left(a_{1}, a_{2}, a_{3}\right)$ and $\left(b_{1}, b_{2}, b_{3}\right)$, respectively, then the operational laws of these two triangular fuzzy numbers are as follows:

$$
\tilde{a} \oplus \tilde{b}=\left(a_{1}, a_{2}, a_{3}\right) \oplus\left(b_{1}, b_{2}, b_{3}\right)=\left(a_{1}+b_{1}, a_{2}+b_{2}, a_{3}+b_{3}\right)
$$

$$
\tilde{a} \otimes \tilde{b}=\left(a_{1}, a_{2}, a_{3}\right) \otimes\left(b_{1}, b_{2}, b_{3}\right) \cong\left(a_{1} \times b_{1}, a_{2} \times b_{2}, a_{3} \times b_{3}\right)
$$

$$
\tilde{r}_{i j}=\left(\tilde{d}_{i 1} \otimes \cdots \otimes \tilde{d}_{i j} \otimes \cdots \otimes \tilde{d}_{i n}\right)^{\frac{1}{n}}
$$

and the normalized weight of each criterion is obtained as follows:

$$
\tilde{r}_{i j}{ }^{\prime}=\tilde{r}_{i j} \otimes\left(\tilde{r}_{i 1} \oplus \cdots \oplus \tilde{r}_{i j} \oplus \cdots \oplus \tilde{r}_{i n}\right)^{-1}
$$

In this paper the normalized fuzzy weights are used to construct fuzzy HOQ of the QFD.

\section{Linear physical programming (LPP)}

LPP is a multi-objective optimization method that develops an aggregate objective function of the criteria in a piecewise, Archimedean-goal-programming fashion. The physical programming approach in its nonlinear (general) form was developed by Messac (1996) and in its piece-wise linear form, LPP, provides the means for Decision makers (DMs) to express his/her priority with respect to each criterion using four classes, i.e., the Decision maker (DM) declares each criterion as belonging to one of four distinct classes. Class functions allowed the Decision makers (DMs) to express the ranges of differing levels of preference for each criterion. A criterion falls into one of four classes of penalty functions, hereby called class functions, which are defined as follows:

Class 1S smaller-is-better, i.e., minimization

Class $2 \mathrm{~S}$ larger-is-better, i.e., maximization

Class $3 S$ value-is-better

Class $4 \mathrm{~S}$ range-is-better

LPP has been used in several diverse applications. Maria et al. (2003) used LPP in production planning. Melachrinoudis et al. (2005) propose a LPP model which enables a decision maker to consider multiple criteria (i.e., cost, customer service, and intangible benefits) and to express criteria preferences not in a traditional form of weights, but in ranges of different degrees of desirability.

Tian and Zuo (2006) proposed a multi-objective optimization model by using physical programming for redundancy allocation for multi-state series-parallel systems.

\section{Applying LPP with QFD}

By applying LPP, the satisfaction level of each customer requirement is classified in one of six different ranges (ideal range, desirable range, tolerable range, undesirable range, highly undesirable range, and unacceptable range). According to the proposed methodology by Lai et al. (2006), each engineering characteristic usually needs cost for improvement. So the last row of the HOQ is the cost index for each engineering characteristic. $X_{j}=(j=1,2, \ldots, q)$ is defined as the value of the engineering characteristic $j$. The normalized value of engineering characteristic $j$ is defined as follows:

$$
\mathrm{x}_{\mathrm{j}}=\mathrm{X}_{\mathrm{j}} / \max \left\{\mathrm{X}_{\mathrm{j}}\right\} \quad \text { and } \quad 0 \leq \mathrm{x}_{\mathrm{j}} \leq 1 .
$$


The proposed algorithm by Messac et al. (1996) to obtain the weights of the different ranges is as follows: The value of a class function $z_{i}$ at the intersection of given ranges is the same for any customer requirement. The loss function $z_{i}(i=1,2, \ldots, p)$ is defined in LPP and can be viewed as a loss of customer satisfaction. $z_{s}$ is defined as the value of class function at range intersection $s$. It can be expressed mathematically as follows:

$$
z_{s} \equiv z_{i}\left(t_{i s}\right) .
$$

$t_{i s}$ is the limit of different ranges, and $s$ denotes a range. $z_{s}$ is a constant for all $i$ and $\tilde{z}^{s}$ and is defined as follows:

$$
\begin{aligned}
& \tilde{z}^{s} \equiv z^{s}-z^{s-1} \quad(2 \leq s \leq 5) \\
& z^{1} \equiv 0 .
\end{aligned}
$$

According to the LPP method, we can define $\tilde{z}^{s}$ as follows:

$$
\tilde{z}^{s}=\beta(p-1) \tilde{z}^{s-1} \quad(3 \leq s \leq 5)
$$

where $p$ denotes the number of customer requirements, and $\beta$ is the convexity parameter. $t_{i s}$ is defined as follows:

$$
\tilde{t}_{i s}=t_{i(s-1)}-t_{i s} \quad(2 \leq s \leq 5) .
$$

The importance weight of each customer satisfaction level is given by

$$
\begin{aligned}
& w_{i s}=\left.\tilde{z}^{s}\right|_{\tilde{t}_{i s}} \quad(2 \leq s \leq 5) \\
& w_{i 1}=0
\end{aligned}
$$

The importance weight of each range for every customer requirement can be calculated as follows:

$$
\tilde{w}_{i s}=w_{i s}-w_{i(s-1)} \quad(2 \leq s \leq 5) .
$$

Finally, by solving the following proposed mathematical model by Lai et al. (2006), the optimal achievement level of the each EC, allocated budget to each EC, and CRs satisfaction level can be determined:

$$
d_{\overline{i s}, x}^{\min } \sum_{i=1}^{p} \sum_{s=2}^{5}\left(\tilde{w}_{i s} d_{i s}^{-}\right)
$$

subject to

$$
\begin{array}{ll}
\sum_{j=1}^{q} r_{i j} x_{j}+d_{i s}^{-} \geq t_{i(s-1)} & i=1, \ldots, p \quad s=2, \ldots, 5 \\
\sum_{j}^{q}=1 & c_{j} x_{j} \leq B \\
d_{i s}^{-} \geq 0 \quad i=1, \ldots, p & s=2, \ldots, 5 \\
0 \leq x_{j} \leq 1 & J=1, \ldots, q .
\end{array}
$$

The deviational variable, denoted by $d_{i s}^{-}$, can be viewed as the distance from the value of the performance rating of customer requirement $i$ under consideration to $t_{i(s-1)}$, starting from the left-hand side. $C_{j}$ is the cost of unit improvement of the engineering characteristic, and $B$ is the cost limit for improvement for all of the engineering characteristics.

\section{Fuzzy linear programming}

Linear programming (LP) is the optimization technique most frequently applied in real-world problems. Any linear programming model representing realworld situations involves a lot of parameters whose values are assigned by experts, so some of these parameters or whole of them can be fuzzy. In this paper, for solving the fuzzy mathematical model, we use Jiménez's approach. According to Jiménez (1996), the expected interval (EI) of triangular fuzzy number $\tilde{d}$ can be defined as follows:

$$
E I(\tilde{d})=\left[E_{1}^{d}, E_{2}^{d}\right]=\left[\frac{1}{2}\left(d^{l}+d^{m}\right), \quad \frac{1}{2}\left(d^{m}+d^{r}\right)\right] .
$$

Moreover, according to the ranking method of Jiménez (1996) for any pair of fuzzy numbers $\tilde{a}$ and $\tilde{b}$, the degree in which $\tilde{a}$ is bigger than $\tilde{b}$ is defined as follows:

$$
\mu_{M}(\tilde{a}, \tilde{b})=\left\{\begin{array}{cc}
0 & \text { if } E_{2}^{a}-E_{1}^{b}<0 \\
\frac{E_{2}^{a}-E_{1}^{b}}{E_{2}^{a}-E_{1}^{b}-\left(E_{1}^{a}-E_{2}^{b}\right)} & \text { if } \quad 0 \in\left[E_{1}^{a}-E_{2}^{b}, E_{2}^{a}-E_{1}^{b}\right] \\
1 & \text { if } \quad E_{1}^{a}-E_{2}^{b}>0 .
\end{array}\right.
$$

When $\mu_{M}(\tilde{a}, \tilde{b})$, it will demonstrate that $\tilde{a}$ is bigger than, or equal, to $\tilde{b}$ at least in a degree $\alpha$ and it will be represented it by $\tilde{a} \geq_{\alpha} \tilde{b}$ for two types of the constraints as the following:

$$
\begin{array}{ll}
\tilde{a}_{i} x \geq \tilde{b}_{i} & i=1, \ldots, m \\
\tilde{a}_{i} x \leq \tilde{b}_{i} & i=m+1, \ldots, t
\end{array}
$$

Table 1 Triangular fuzzy conversion scale

\begin{tabular}{ccc}
\hline Linguistic scale & $\begin{array}{c}\text { Triangular } \\
\text { fuzzy scale }\end{array}$ & $\begin{array}{c}\text { Triangular fuzzy } \\
\text { reciprocal scale }\end{array}$ \\
\hline Equal & $(1,1,1)$ & $(1,1,1)$ \\
Weak & $(2 / 3,1,3 / 2)$ & $(2 / 3,1,3 / 2)$ \\
Fairly strong & $(3 / 2,2,5 / 2)$ & $(2 / 5,1 / 2,2 / 3)$ \\
Very strong & $(5 / 2,3,7 / 2)$ & $(2 / 7,1 / 3,2 / 5)$ \\
Absolute & $(7 / 2,4,9 / 2)$ & $(2 / 9,1 / 4,2 / 7)$ \\
\hline
\end{tabular}


Collecting information of the different level of SCM to determine requirements and engineering characteristics (ECs) of each level

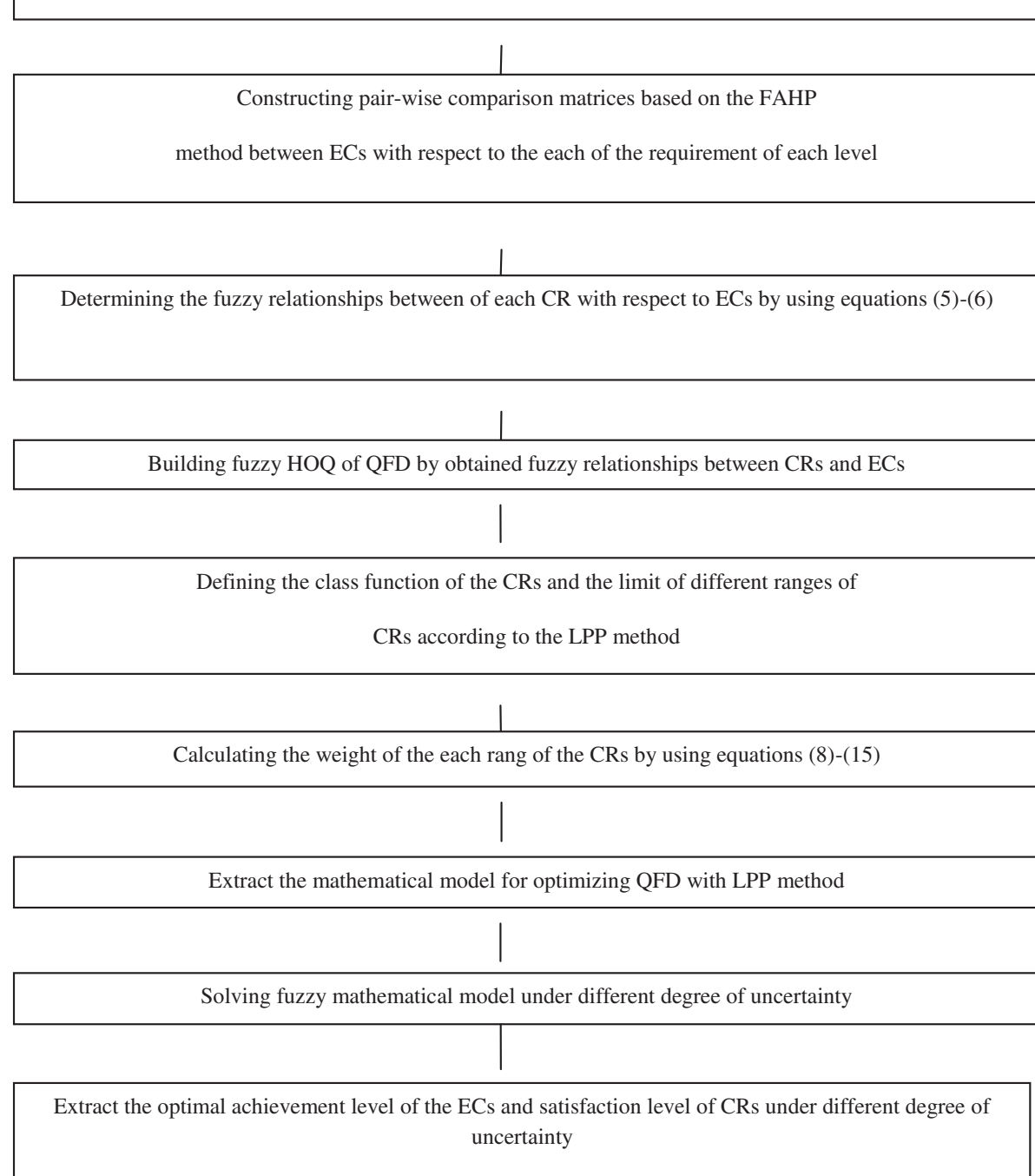

Figure 1 Step-wise procedure.

According to the Jiménez et al. (2007), a decision vector $x \in \mathfrak{R}^{n}$ is feasible in degree $\alpha$ if $\min _{i=1, \ldots, m}=$ $\left\{\mu_{M}\left(\tilde{a}_{i} x, b_{i}\right)\right\}=\alpha$. According to Equation 20, the equation $\tilde{a}_{i} x \geq b_{i}$ is equivalent to the following:

$$
\frac{E_{2}^{a_{i} x}-E_{1}^{b_{i}}}{E_{2}^{a_{i} x}-E_{1}^{a_{i} x}+E_{2}^{b_{i}}-E_{1}^{b_{i}}} \geq \alpha \quad i=1, \ldots, m .
$$

So the equation can be rewritten as follows:

$$
\left[(1-\alpha) E_{2}^{a_{i}}+\alpha E_{1}^{a_{i}}\right] x \geq \alpha E_{2}^{b_{i}}+(1-\alpha) E_{1}^{b_{i}} \quad i=1, \ldots, m . \quad \text { Punctuality }
$$

We can do this for $\tilde{a}_{i} x \leq b_{i}$, so this is equation equiva- Lead time lent to the following respectively:
Table 2 Important CRs and ECs

\begin{tabular}{ll}
\hline Customer requirements & \multicolumn{1}{c}{ Engineering characteristics } \\
\hline Cost & $\mathrm{EF}=$ experience of the sector \\
Conformity & $\begin{array}{l}\mathrm{IN}=\text { capacity for innovation to follow up } \\
\text { the customer's evolution in terms of } \\
\text { changes in its strategy and market } \\
\\
\text { Punctuality }\end{array}$ \\
Efficacy & $\mathrm{SL}=$ quality system certification \\
& $\begin{array}{l}\text { customer's requests } \\
\text { Lead time }\end{array}$ \\
& $\mathrm{RR}=$ ability to manage orders on-line \\
& (EDI-system) \\
\hline
\end{tabular}


Table 3 Pair-wise comparison matrix between the engineering characteristics with respect to the cost

\begin{tabular}{cccccc}
\hline Cost & EF & IN & SQ & FL & RP \\
\hline EF & $(1,1,1)$ & $(1,1,1)$ & $(3 / 2,2,5 / 2)$ & $(2 / 3,1,3 / 2)$ & $(2 / 3,1,3 / 2)$ \\
IN & $(1,1,1)$ & $(1,1,1)$ & $(2 / 5,1 / 2,2 / 3)$ & $(1,1,1)$ & $(2 / 3,1,3 / 2)$ \\
SQ & $(2 / 5,1 / 2,2 / 3)$ & $(3 / 2,2,5 / 2)$ & $(1,1,1)$ & $(3 / 2,2,5 / 2)$ & $(1,1,1)$ \\
FL & $(2 / 31,3 / 2)$ & $(1,1,1)$ & $(2 / 5,1 / 2,2 / 3)$ & $(1,1,1)$ & $(2 / 3,1,3 / 2)$ \\
RP & $(2 / 3,1,3 / 2)$ & $(2 / 3,1,3 / 2)$ & $(1,1,1)$ & $(2 / 3,1,3 / 2)$ & $(1,1,1)$ \\
\hline
\end{tabular}

$$
\left[\alpha E_{2}^{a_{i}}+(1-\alpha) E_{1}^{a_{i}}\right] x \leq \alpha E_{1}^{b_{i}}+(1-\alpha) E_{2}^{b_{i}} \quad i=m+1, \ldots, t .
$$

In this paper Jiménez's approach is used to solve the mathematical model.

\section{Proposed methodology}

Because of the ambiguity and fuzziness of the real-world problems, crisp number cannot deal with the problem carefully. We extended Lai et al.'s (2006) proposed methodology by combining FAHP method to construct HOQ with the fuzzy numbers. Triangular fuzzy number in Table 1 is used for weighting the ECs with respect to the each CR. So Equation 17 is converted to the following equation:

$$
\sum_{j=1}^{q} \tilde{r}_{i j}{ }^{\prime} \mathrm{x}_{\mathrm{j}}+d_{i s}^{-} \geq t_{i(s-1)} \quad i=1, \ldots, p \quad s=2, \ldots, 5
$$

where $\tilde{r}_{i j}{ }^{\prime}$ is triangular fuzzy number which is obtained by geometric mean method based on the pair-wise comparison according to FAHP. We use Jiménez's approach to solve the mathematical model. In Figure 1, the stepwise procedure of the proposed methodology is shown.

\section{Numerical example}

We illustrate our proposed methodology step by step by solving an example of supplier development:

Step 1. Information about company requirements and characteristics of the suppliers to satisfy these requirements are collected. Important CRs and ECs are shown in Table 2.
Step 2. Pair-wise comparison matrices based on the FAHP method between ECs with respect to the each of the CRs are constructed. For example, the relationship between the engineering characteristics with respect to the cost is shown in Table 3. Similarly, other pair-wise comparison matrices can be obtained.

Step 3. Fuzzy relationships of each CR with respect to ECs by using Equations 3, 4, 5, and 6 according to the geometric mean method are determined. For example, the fuzzy relationships between the first requirement and ECs are determined as follows:

$$
\begin{aligned}
\tilde{r}_{11}= & \left(\tilde{d}_{11} \otimes \tilde{d}_{12} \otimes \tilde{d}_{13} \otimes \tilde{d}_{14} \otimes \tilde{d}_{15}\right)^{1 / 5} \\
\tilde{r}_{11}= & \left((1 \times 1 \times \ldots \times 2 / 3)^{1 / 5}, \quad(1 \times 1 \times \ldots \times 1)^{1 / 5},\right. \\
& \left.(1 \times 1 \times \ldots \times 3 / 2)^{1 / 5}\right)=(0.922,1.149,1.413)
\end{aligned}
$$

Similarly, we can compute the remaining $\tilde{r}_{i j}$, which are the following:

$$
\begin{array}{ll}
\tilde{r}_{12}=(0.708,0.871,1.084), & \tilde{r}_{13}=(0.979,1.149,1.33), \\
\tilde{r}_{14}=(0.653,0.871,1.176), & \tilde{r}_{15}=(0.784,0.871,1.275) .
\end{array}
$$

We normalized the calculated weights as follows:

$$
\begin{aligned}
& \tilde{r}_{11}{ }^{\prime}=\tilde{r}_{11} \otimes\left(\tilde{r}_{11} \oplus \tilde{r}_{12} \oplus \tilde{r}_{13} \oplus \tilde{r}_{14} \oplus \tilde{r}_{15}\right)^{-1} \\
& \tilde{r}_{11}{ }^{\prime}=(0.922,1.149,1.413) \otimes((0.922,1.149,1.413) \\
& \oplus \ldots \oplus 0.784, \quad 0.871,1.275))^{-1} \\
& =\left(\begin{array}{lll}
0.1, & 0.15,0.23)
\end{array}\right)
\end{aligned}
$$

The remaining $\tilde{r}_{i j}{ }^{\prime}$ values are as follows:

\begin{tabular}{|c|c|c|c|c|c|c|c|c|c|c|c|c|c|c|c|}
\hline & $\mathrm{EC}_{1}$ & & & $\mathrm{EC}_{2}$ & & & $\mathrm{EC}_{3}$ & & & $\mathrm{EC}_{4}$ & & & $\mathrm{EC}_{5}$ & & \\
\hline $\mathrm{EC}_{1}$ & 0.10 & 0.15 & 0.23 & 0.11 & 0.15 & 0.22 & 0.15 & 0.21 & 0.28 & 0.09 & 0.15 & 0.23 & 0.11 & 0.16 & 0.29 \\
\hline $\mathrm{EC}_{2}$ & 0.10 & 0.15 & 0.23 & 0.11 & 0.16 & 0.23 & 0.12 & 0.17 & 0.23 & 0.11 & 0.15 & 0.24 & 0.12 & 0.18 & 0.26 \\
\hline $\mathrm{EC}_{3}$ & 0.12 & 0.19 & 0.30 & 0.11 & 0.17 & 0.25 & 0.11 & 0.15 & 0.19 & 0.14 & 0.21 & 0.31 & 0.09 & 0.14 & 0.21 \\
\hline $\mathrm{EC}_{4}$ & 0.13 & 0.19 & 0.27 & 0.11 & 0.17 & 0.27 & 0.12 & 0.16 & 0.21 & 0.09 & 0.12 & 0.15 & 0.13 & 0.21 & 0.31 \\
\hline $\mathrm{EC}_{5}$ & 0.12 & 0.17 & 0.26 & 0.12 & 0.20 & 0.32 & 0.10 & 0.14 & 0.20 & 0.14 & 0.19 & 0.26 & 0.09 & 0.14 & 0.21 \\
\hline
\end{tabular}

$$
\begin{aligned}
& \tilde{r}_{12}{ }^{\prime}=\left(\begin{array}{lll}
0.1, & 0.15, & 0.23
\end{array}\right), \quad \tilde{r}_{13}{ }^{\prime}=\left(\begin{array}{lll}
0.15 & 0.21, & 0.28
\end{array}\right), \\
& \tilde{r}_{14}{ }^{\prime}=\left(\begin{array}{lll}
0.09, & 0.15, & 0.23
\end{array}\right), \quad \tilde{r}_{15}{ }^{\prime}=\left(\begin{array}{lll}
0.11, & 0.16, & 0.29
\end{array}\right) \text {. }
\end{aligned}
$$

Step 4. Fuzzy HOQ of QFD is constructed by fuzzy relationships. Table 4 is has shown the fuzzy HOQ which is build by applying FAHP.

Step 5. Table 5 is shown the class function of the CRs and the limit of different ranges of CRs.

Step 6. After determining the limit of different ranges, the weight of the each range of the CRs according to the Messac et al. (1996) $\beta=1.1$ and $z^{2}=0.1$

\section{Table 4 Fuzzy HOQ of the QFD}


Table 5 Class function of the CRs and the limit of different ranges of CRs

\begin{tabular}{ccccccc}
\hline $\begin{array}{c}\text { Customer } \\
\text { requirements }\end{array}$ & $\begin{array}{c}\text { Class } \\
\text { function }\end{array}$ & \multicolumn{5}{c}{$\begin{array}{c}\text { The limit of different ranges of CRs } \\
\text { according to the LPP method }\end{array}$} \\
\cline { 3 - 7 } & & $\boldsymbol{t}_{\mathbf{1}}$ & $\boldsymbol{t}_{\mathbf{2}}$ & $\boldsymbol{t}_{\mathbf{3}}$ & $\boldsymbol{t}_{\mathbf{4}}$ & $\boldsymbol{t}_{\mathbf{5}}$ \\
\hline Cost & $1 \mathrm{~S}$ & 0.14 & 0.36 & 0.57 & 0.71 & 1 \\
Conformity & $2 S$ & 1 & 0.89 & 0.74 & 0.47 & 0.32 \\
Punctuality & $2 S$ & 1 & 0.7 & 0.55 & 0.3 & 0.1 \\
Efficacy & $2 S$ & 1 & 0.75 & 0.65 & 0.5 & 0.2 \\
Lead time & $1 S$ & 0 & 0.29 & 0.57 & 0.86 & 1 \\
\hline
\end{tabular}

(small positive number) is calculated by applying

Equations 8, 9, 10, 11, 12, 13, 14, and 15.

The weights of the different ranges of the cost are as following:

$$
\begin{array}{ll}
\tilde{w}_{12}=0.001, & \tilde{w}_{13}=1.587, \\
\tilde{w}_{14}=11.499, & \tilde{w}_{15}=16.262
\end{array}
$$

The weights of the other customer requirement can be defined similarly.

Step 7. Using Equations 16, 17, 18, 19, and 20, we extract the mathematical model of the problem. We exchange the Equation 17 with Equation 28 in our model. Now we have a model with fuzzy constraints. Step 8. Applying the Equations 26 and 27, the fuzzy model is exchanged to the LP model. We solved the model with different degrees of uncertainty. Tables 6 and 7 showed the optimal achievement levels of ECs and CRs under different degrees of uncertainty which are obtained by solving the model.

\section{Discussion of results}

The obtained results of this numerical example in Table 6 show that in engineering characteristics, $x_{3}$ and $x_{4}$ which demonstrate respectively quality system certification and flexibility of response to the customer's requests, have not been fully achieved in some degree

Table 6 Optimal achievement levels of the ECs under different values of $a$

\begin{tabular}{lccccc}
\hline $\boldsymbol{a}$ & \multicolumn{5}{c}{$\begin{array}{c}\text { Optimal achievement levels of the ECs } \\
\text { under different values of } \boldsymbol{\alpha}\end{array}$} \\
\cline { 2 - 6 } & $\boldsymbol{x}_{\mathbf{1}}$ & $\boldsymbol{x}_{\mathbf{2}}$ & $\boldsymbol{x}_{\mathbf{3}}$ & $\boldsymbol{x}_{\mathbf{4}}$ & $\boldsymbol{x}_{\mathbf{5}}$ \\
\hline 0.5 & 1 & 1 & 1 & 0 & 1 \\
0.6 & 1 & 1 & 1 & 0.02 & 1 \\
0.7 & 1 & 1 & 1 & 0.17 & 1 \\
0.8 & 1 & 1 & 0.7 & 0.44 & 1 \\
0.9 & 1 & 1 & 0.69 & 0.29 & 1 \\
1 & 1 & 1 & 0.69 & 0.16 & 1 \\
\hline
\end{tabular}

Table 7 Optimal achievement levels of the CRs under different values of $a$

\begin{tabular}{cccccc}
\hline $\boldsymbol{a}$ & \multicolumn{5}{c}{ Satisfaction levels of the CRs under different values of $\boldsymbol{a}$} \\
\cline { 2 - 6 } & $\mathbf{C R}_{\mathbf{1}}$ & $\mathbf{C R}_{\mathbf{2}}$ & $\mathbf{C R}_{\mathbf{3}}$ & $\mathbf{C R}_{\mathbf{4}}$ & $\mathbf{C R}_{\mathbf{5}}$ \\
\hline 0.5 & 2.17 & 2.07 & 2.03 & 2.29 & 2.05 \\
0.6 & 2.18 & 2.08 & 2.04 & 2.29 & 2.06 \\
0.7 & 2.25 & 2.16 & 2.14 & 2.35 & 2.15 \\
0.8 & 2.18 & 2.13 & 2.18 & 2.3 & 2.18 \\
0.9 & 2.11 & 2.06 & 2.07 & 2.24 & 2.09 \\
1 & 2.05 & 1.99 & 1.99 & 2.19 & 2.01 \\
\hline
\end{tabular}

of uncertainty, while the other three characters have been obtained completely in all calculated degree of uncertainty.

The results of Table 7 indicate that the satisfaction level of $\mathrm{CR}_{4}$ is rather higher than the other four requirements, so in this example, efficacy is more important than cost, conformity, punctuality, and lead time. Unlike the existing literature, this method integrates three different concepts such as AHP, QFD, and LPP to achieve the optimal values of the ECs and CRs under different degrees of uncertainty. So with respect to the company strategy, managers can use the results of proposed method to improve and develop engineering characteristics of suppliers in order to meet their requirements.

\section{Conclusions}

In this paper we proposed a simple and useful methodology by integrating AHP, QFD, and LPP for supplier development problems under uncertainty conditions. We used fuzzy AHP to determine the relationships between customer's requirements and engineering characteristics for building the relation matrix in the QFD method. Then, applying LPP, we formulated the mathematical model to optimize QFD. Proposed methodology helps decision makers to deal with the vagueness and impreciseness involved in the real problems. In addition, it helps them to maximize overall customer satisfaction in supplier development. Also, the proposed methodology can be used in the product design, product development, process development, and other decision making problems.

For the future work, we suggest to consider the correlation between engineering characteristics to increase the reliability of the obtained solutions or use the other type of fuzzy programming to obtain optimal achievement level of engineering characteristics and customer satisfaction level.

Competing interests

The authors declare that there is no conflict of interests. 


\section{Authors' contributions}

All authors ZS, ER and FM, have made adequate effort on all parts of the work necessary for the development of this manuscript according to his/her expertise. All authors read and approved the final manuscript.

\section{Author details}

${ }^{1}$ Department of Industrial Engineering, Khaje Nasir Toosi University of Technology, Tehran, Iran. ${ }^{2}$ Department of Management and Economics, Tarbiat Modares University, Jalal Ale Ahmad Highway, P.O.BOX: 14115-111, Tehran, Iran.

Received: 23 July 2013 Accepted: 20 December 2013

Published: 10 Jan 2014

\section{References}

Aydogan EK (2011) Performance measurement model for Turkish aviation firms using the rough-AHP and TOPSIS methods under fuzzy environment. Expert Syst Appl 38:3992-3998

Bevilacqua M, Ciarapica FE, Giacchetta G (2006) A fuzzy-QFD approach to supplier selection. J Purchas Suppl Manag 12:14-27

Bhattacharya A, Geraghty J, Young P (2010) Supplier selection paradigm: an integrated hierarchical QFD methodology under multiple-criteria environment. Appl Soft Comput 10:1013-1027

Bottani E (2009) A fuzzy QFD approach to achieve agility. Int J Prod Econ 119 (2):380-391

Bottani E, Rizzi A (2006) Strategic management of logistics service: a fuzzy-QFD approach. Int J Prod Econ 103(2):585-599

Buckley JJ (1985) Fuzzy hierarchical analysis. Fuzzy Set Syst 17(1):233-247

Chan FTS, Kumar N (2007) Global supplier development considering risk factors using fuzzy extended AHP-based approach. Omega, Int J Manag Sci $35: 417-431$

Chang DY (1992) Extent analysis and synthetic decision, optimization techniques and applications, vol 1. World Scientific, Singapore, 352

Chang DY (1996) Applications of the extent analysis method on fuzzy AHP. Eu J Operat Res 95:649-655

Chen LH, Ko WC (2008) A fuzzy nonlinear model for quality function deployment considering Kano's concept. Math Comput Model 48:581-593

Chen LH, Ko WC (2009) Fuzzy linear programming models for new product design using QFD with FMEA. Appl Math Model 33:633-647

Chen LH, Ko WC (2010) Fuzzy linear programming models for NPD using a four-phase QFD activity process based on the means-end chain concept. Eur J Operat Res 201:619-632

Chen LH, Weng MC (2006) An evaluation approach to engineering design in QFD processes using fuzzy goal programming models. Eur J Operat Res 172:230-248

Chen MF, Tseng GH, Ding CG (2008) Combining fuzzy AHP with MDS in identifying the preference similarity of alternatives. Appl Soft Comput 8:110-117

Cox A (1999) Power value and supply chain management. Supply Chain Management. Int J 4(4):167-175

Delice EK, Güngör Z (2009) A new mixed integer linear programming model for product development using quality function deployment. Comput Indust Eng 57:906-912

Fung RYK, Chen Y, Chen L, Tang J (2005) A fuzzy expected value-based goal programming model for product planning using quality function deployment. Eng Optimization 37(6):633-647

Gebennini E, Gamberinni R, Manzini R (2009) An integrated productiondistribution model for the dynamic location and allocation problem with safety stock optimization. Int J Prod Econ 122:286-304

Güngör Z, Serhadlığlu G, Kesen SE (2009) A fuzzy AHP approach to personnel selection problem. Appl Soft Comput 9:641-646

Haghighi M, Divandari A, Keimasi M (2010) The impact of 3D e-readiness on e-banking development in Iran: a fuzzy AHP analysis. Expert Syst Appl 37:4084-4093

Hassanzadeh Amin S, Razmi J (2009) An integrated fuzzy model for supplier management: a case study of ISP selection and evaluation. Expert Syst Appl 36:8639-8648

Jiménez M (1996) Ranking fuzzy numbers through the comparison of its expected intervals. Int J Uncertainty, Fuzziness Knowledge-Based Syst 4 (4):379-388
Jiménez M, Arenas M, Bilbao A, Rodriguez MV (2007) Linear programming with fuzzy parameters: an interactive method resolution. Eur J Oper Res 177:1599-1609

Kahraman C, Cebeci U, Ruan D (2004) Multi-attribute comparison of catering service companies using fuzzy AHP: the case of Turkey. Int J Prod Econ 87:171-184

Kahraman C, Ertay T, Büyüközkan G (2006) A fuzzy optimization model for QFD planning process using analytic network process. Eur J Oper Res 171:390-411

Lai X, Xie M, Tan KC (2006) QFD optimization using linear physical programming. Eng Optimization 38(5):593-607

Lai X, Xie M, Tan KC (2007) Optimizing product design using quantitative quality function deployment: a case study. Qual Reliability Eng Int 23:45-572

Maria A, Mattson CA, Ismail-Yahaya A, Messac A (2003) Linear physical programming for production optimization. Eng Optimization 35(1):19-37

Melachrinoudis E, Messac A, Min H (2005) Consolidating a warehouse network: a physical programming approach. Int J Prod Econ 97:1-17

Messac A (1996) Physical programming: effective optimization for computational design. AIAA J 34(1):149-158

Messac A, Gupta SM, Akbulut B (1996) Linear physical programming: a new approach to multiple objective optimization. Trans Oper Res 8:39-59

Park T, Kim K (1998) Determination of an optimal set of design requirements using house of quality. J Oper Manage 16:569-581

Raharjo H, Brombacher AC, Xie M (2008) Dealing with subjectivity in early product design phase: a systematic approach to exploit Quality Function Deployment potentials. Comp Ind Eng 55:253-278

Raissi S, Izadi M, Saati S (2011) A novel method on customer requirements preferences based on common set of weight. Aust J Basic Appl Sci 5 (6):1544-1552

Raissi S, Izadi M, Saati S (2012) Prioritizing engineering characteristic in QFD using fuzzy common set of weight. Am J Sci Res 49:34-49

Rung Yu J, Shing WY (2013) Fuzzy analytic hierarchy process and analytic network process: an integrated fuzzy logarithmic preference programming. Appl Soft Comput 13:1792-1799

Sener Z, Karsak EE (2011) A combined fuzzy linear regression and fuzzy multiple objective programming approach for setting target levels in quality function deployment. Expert Syst Appl 38:3015-3022

Sharma JR, Rawani AM (2008) Quality function deployment: integrating comprehensive matrix and SWOT analysis for effective decision making. J Ind Eng Int 4(6):19-31

Soota t, Singh H, Mishra RC (2011) Fostering product development using combination of QFD and ANP: a case study. J Ind Eng Int 7(14):29-40

Tian Z, Zuo MJ (2006) Redundancy allocation for multi-state systems using physical programming and genetic algorithms. Reliability Eng Syst Saf 91:1049-1056

Xia W, Wu Z (2007) Supplier selection with multiple criteria in volume discount environments. Omega 35(5):494-504

Yousefi S, Mohammadi M, Haghighat Monfared J (2011) Selection effective management tools on setting European Foundation for Quality Management (EFQM) model by a quality function deployment (QFD) approach. Expert Syst Appl 38:9633-9647

Zarei M, Fakhrzad MB, Jamali Paghaleh M (2011) Food supply chain leanness using a developed QFD model. J Food Eng 102:25-33

\subsection{6/2251-712X-10-2}

Cite this article as: Shad et al:: Integration of QFD, AHP, and LPP

methods in supplier development problems under uncertainty. Journal of Industrial Engineering International 2014, 10:2 